\title{
Effectiveness of home care programmes for patients with incurable cancer on their quality of life and time spent in hospital: systematic review
}

\author{
Frank W J M Smeenk, Jolanda C M van Haastregt, Luc P de Witte, Harry F J M Crebolder
}

\begin{abstract}
Objective: To investigate whether for patients with incurable cancer comprehensive home care programmes are more effective than standard care in maintaining the patients' quality of life and reducing their "readmission time" (percentage of days spent in hospital from start of care till death).

Design: Systematic review.

Methods: A computer aided search was conducted using the databases of Medline, Embase, CancerLit, and PsychLit. The search for studies and the assessment of the methodological quality of the relevant studies were performed by two investigators, blinded from each other. Prospective, controlled studies investigating the effects of a home care intervention programme on patients' quality of life or on readmission time were included in the analyses. Results: Only 9 prospective controlled studies were found; eight were performed in the United States and 1 in the United Kingdom. Their methodological quality was judged to be moderate (median rating 62 on a 100 point scale). None of the studies showed a negative influence of home care interventions on quality of life. A significantly positive influence on the outcome measures was seen in 2 out of the 5 studies measuring patients' satisfaction with care, in $3 / 7$ studies measuring physical dimensions of quality of life, in $1 / 6$ studies measuring psychosocial dimensions, and in $2 / 5$ studies measuring readmission time. The incorporation of team members' visits to patients at home or regular multidisciplinary team meetings into the intervention programme seemed to be related to positive results. Conclusions: The effectiveness of comprehensive home care programmes remains unclear. Given the enormity of the problems faced by society in caring for patients with terminal cancer, further research is urgently needed.
\end{abstract}

\section{Introduction}

In developed countries cancer remains one of the major causes of death, despite all the highly sophisticated treatment methods. ${ }^{1}$ Fifty per cent of all patients with cancer still cannot be cured. ${ }^{2}{ }^{3}$ The quality of life of the patients with incurable cancer inevitably diminishes, ${ }^{4}$ and they are frequently readmitted to hospital. ${ }^{5}{ }^{6}$ Readmission occurs mainly because aggravating symptoms of the disease can no longer be treated at home; "caring" has temporarily become too demanding for the informal caregivers; or there is a lack of care coordination between the different professional caregivers. ${ }^{7-10}$ The high readmission rate partly explains the high medical costs of treating these patients, especially in the terminal stage. ${ }^{11}$ Moreover, most of these patients would prefer to be at home dur-

\section{Search strategy and key words used}

["Home care" or "home nursing"] and

["Cancer" or "neoplasm(s)"] and

["Quality of life" or "well being" or "readmission" or "hospitali(s/z)ation"]

ing this last stage of their illness. ${ }^{12-13}$ Home care programmes have therefore been developed for these patients in the hope that they will be able to stay at home for longer and maintain an acceptable quality of life. ${ }^{414}$ We investigated the literature with the principle aim of determining whether such programmes are effective.

\section{Methods}

Publications were selected from the following databases: Medline (1985-97), Embase (1984-97), CancerLit (1979-97), and PsychLit (1974-97) (see box for key words and search strategy). No language restrictions were imposed. ${ }^{16}$ Other search strategies were also performed, including use of key words such as "hospice," "terminal care," and "palliative care." These searches, however, revealed no additional articles that could be included in our review.

The following selection criteria were used for inclusion of studies in the analysis:

- The study population had to include patients with incurable cancer and a control group against which the intervention could be compared

- The study design had to be prospective

- The intervention had to be aimed at different aspects of care, and its main goal had to be better support for patients at home; studies of specific home care interventions aimed at just one aspect of care- such as home parenteral nutrition or pain treatment-were to be excluded

- The control group had to have received standard available (home) care; studies in which the control group received only hospital care were to be excluded - The dependent variables in the study had to include at least one dimension of quality of life or the readmission rate of patients.

A consensus meeting was planned to deal with any disagreements that arose between the two investigators (FWJMS and JCMvanH) in the selection of the articles. If no agreement could be reached a third investigator (LPdeW) decided whether the paper should be included. The reference lists of these selected papers were screened for other relevant studies.

Criteria based analysis was performed on the selected papers to assess their methodological quality. Standardised analyses were performed by two investigators (FWJMS and JCMvanH). To prevent bias, the
Departments of

Multidisciplinary

Oncology and

Pulmonology,

Catharina Hospital

PO Box 1350,

5602 ZA

Eindhoven,

Netherlands

Frank W J M

Smeenk,

pulmonologist

Institute for

Rehabilitation

Research (IRV), PO

Box 192, $6430 \mathrm{AD}$

Hoensbroek,

Netherlands

Jolanda C M van

Haastregt,

health scientist

Health Care

Interventions and

Services

Department,

Institute for

Rehabilitation

Research (IRV), PO

Box 192, $6430 \mathrm{AD}$

Hoensbroek

Luc $\mathrm{P}$ de Witte,

executive director

Department of

General Practice,

Maastricht

University, PO Box

616, $6200 \mathrm{MD}$

Maastricht,

Netherlands

Harry F J M

Crebolder,

professor of general

practice

Correspondence to:

Dr Smeenk fsk@

iaehv.nl

BMJ 1998;316:1939-44 
Table 1 Criteria for methodological assessment of clinical trials used to review studies of home care programmes for patients with incurable cancer

\begin{tabular}{lc} 
Criterion & Weight \\
\hline Study population & 6 \\
\hline A: Selection and homogeneity & 11 \\
\hline B: Design & 9 \\
\hline C: Comparability of groups & 6 \\
\hline D: Drop out handling & 15 \\
\hline E: Number of patients included & 15 \\
\hline Interventions & 6 \\
\hline F: Description of interventions and standard care & 5 \\
\hline G: Simultaneous interventions & 8 \\
\hline Effect & 6 \\
\hline H: Blinding of people who collected outcome measures \\
\hline I: Use of appropriate outcome measures \\
\hline J: Follow up \\
\hline Data presentation and analysis \\
\hline K: Statistical analysis \\
\hline L: Data presentation & 10 \\
\hline Total & 100 \\
\hline
\end{tabular}

See appendix for more details.

journal name, authors' names, title, summary, and discussion paragraphs were deleted from the articles, and the reviewers were blinded from each other. The articles were scored with strict criteria that addressed the methodological quality (see appendix and table 1), which were based on generally accepted principles. ${ }^{17}$ Once again a consensus meeting followed to tackle any disagreements, and, if necessary, a third investigator (LPdeW) made the final decision.

Essential characteristics of each home care intervention programme and its main outcome measures were assessed. These characteristics comprised the country in which the investigation took place; where the intervention was based (for example, hospital or clinic); the kind of care received by the control group; and the kind of intervention that was investigated.

Data on readmission to hospital are presented as "readmission time" for all studies so that the various results can be compared; readmission time was defined as the percentage of days that the patient spent in hos- pital from the start of care until death. For this, we had to calculate the readmission time in most studies, using the data presented in the articles.

Finally, we tried to relate the results of the studies to their methodological quality and the type of intervention used in the studies.

\section{Results}

\section{Results of search}

The search resulted in 358 articles. Of these articles, nine met our inclusion criteria. ${ }^{14}{ }^{15-24}$ The overall agreement on the inclusion of articles was $100 \%$. Three articles described the results of the national hospice study in the United States. ${ }^{19-21}$ Two of these showed considerable overlap, so they were combined.$^{19}{ }^{20}$ One study ${ }^{22}$ seemed to report the findings of a subgroup analysis of a previous published study. ${ }^{15}$

\section{Methodological quality of studies}

The methodological quality of the studies is shown in table 2. The initial disagreement on the methodological score between the two investigators was 9.2\% (34 items in 8 articles $=272$ items that had to be scored; initially 25 items were scored differently by the reviewers). Most disagreement was the result of errors in reading and interpretation and was easily resolved in a subsequent consensus meeting by the two investigators.

The scores for methodological quality ranged from 48 to 68 (mean 59) out of a possible 100. The median score was 62 , showing that the studies were of moderate methodological quality. The most common shortcomings were in the areas of study population homogeneity; comparability of intervention and control groups; handling of drop outs; and blinding procedure for those who collected the outcome measures.

Characteristics of intervention and standard care

The characteristics of intervention and standard care are shown in table 3. The interventions were hospital

Table 2 Methodological quality of studies of home care programmes for patients with incurable cancer

\begin{tabular}{|c|c|c|c|c|c|c|c|c|c|c|c|c|c|c|c|}
\hline \multirow[b]{2}{*}{ Study } & \multirow{2}{*}{$\begin{array}{c}\text { No of patients } \\
\text { (intervention } \\
\text { group/control } \\
\text { group) }\end{array}$} & \multirow[b]{2}{*}{$\begin{array}{c}\text { Randomised } \\
\text { design }\end{array}$} & \multicolumn{12}{|c|}{ Methodological criteria (score)* } & \multirow[b]{2}{*}{$\begin{array}{l}\text { Methods score } \\
(\max 100)\end{array}$} \\
\hline & & & $A(6)$ & B (11) & C (9) & $D(6)$ & $E(15)$ & $F(15)$ & G (6) & H (5) & I (8) & $J(6)$ & $K(10)$ & $L(3)$ & \\
\hline $\begin{array}{c}\text { Zimmer et al } \\
(1985)^{18} \\
\end{array}$ & $85 / 82$ & Yes & 1 & 7 & 4 & 2 & 15 & 9 & 6 & - & 8 & 6 & 6 & - & 64 \\
\hline $\begin{array}{l}\text { National hospice } \\
(1986)^{1920}\end{array}$ & $1457 / 297 \dagger$ & No & 6 & - & 3 & - & 15 & 5 & 6 & - & 6 & 6 & 6 & 3 & 56 \\
\hline $\begin{array}{l}\text { Wallston et al } \\
(1988)^{21}\end{array}$ & $880 \ddagger$ & No & 6 & - & - & - & 15 & 5 & 6 & - & 4 & 3 & 6 & 3 & 48 \\
\hline $\begin{array}{l}\text { McCorkle et al } \\
(1989)^{14}\end{array}$ & $166 \ddagger$ & Yes & 1 & 7 & 3 & - & 9 & 12 & 6 & - & 8 & 6 & 6 & 3 & 61 \\
\hline $\begin{array}{l}\text { Cummings et al } \\
(1990)^{15}\end{array}$ & $211 / 208$ & Yes & 1 & 7 & 3 & 2 & 15 & 10 & 6 & - & 8 & 6 & 6 & - & 64 \\
\hline $\begin{array}{l}\text { Hughes et al } \\
(1992)^{22}\end{array}$ & $86 / 85$ & Yes & 1 & 7 & 3 & - & 15 & 11 & 6 & - & 8 & 6 & 6 & - & 63 \\
\hline $\begin{array}{l}\text { Addington-Hall } \\
\text { et al }(1992)^{24}\end{array}$ & $318 / 236$ & Yes§ & 1 & 4 & 4 & 3 & 15 & 10 & 6 & 5 & 8 & 3 & 6 & 3 & 68 \\
\hline $\begin{array}{l}\text { McCorkle et al } \\
(1994)^{23}\end{array}$ & $88 / 50$ & No & 1 & - & 4 & 1 & 6 & 5 & 6 & - & 8 & 6 & 10 & 3 & 50 \\
\hline
\end{tabular}

In the national hospice study for evaluation of the methodological quality the article by Greer et a ${ }^{19}$ was used; for the evaluation of the readmission time the article by Mor er a $\left.\right|^{20}$ was used.

* see table 1 and appendix for description of A-L.

†Numbers of patients mentioned in the article by Greer et al ${ }^{19}$ (numbers of patients in study by Mor et $\mathrm{al}^{20}: 5295 / 558$ ).

fOnly the total number of patients was presented.

§The practices from which the patients were derived (but not the patients) were randomised, resulting in incomparable patient groups. 
Table 3 Essential intervention characteristics in studies of home care programmes for patients with incurable cancer

\begin{tabular}{|c|c|c|c|c|c|c|c|c|c|c|c|}
\hline \multirow[b]{2}{*}{ Study } & \multirow[b]{2}{*}{ Country } & \multirow[b]{2}{*}{$\begin{array}{c}\text { Base of } \\
\text { intervention }\end{array}$} & \multirow[b]{2}{*}{$\begin{array}{l}\text { Multicentre } \\
\text { study? }\end{array}$} & \multicolumn{6}{|c|}{ Intervention characteristics } & \multicolumn{2}{|c|}{$\begin{array}{l}\text { Characteristics of standard } \\
\text { care (control) }\end{array}$} \\
\hline & & & & $24 \mathrm{~h}$ service & $\begin{array}{l}\text { Home } \\
\text { visiting }\end{array}$ & $\begin{array}{l}\text { Home care } \\
\text { dossier }\end{array}$ & $\begin{array}{l}\text { Technical } \\
\text { care }\end{array}$ & Training* & $\begin{array}{c}\text { Team } \\
\text { meetings }\end{array}$ & GP available & $\begin{array}{c}\text { Community } \\
\text { nurse }\end{array}$ \\
\hline $\begin{array}{l}\text { Zimmer et al } \\
(1985)^{18} \\
\end{array}$ & USA & $\begin{array}{l}\text { Rehabilitation } \\
\text { centre }\end{array}$ & No & Yes & Yes & Not stated & Not stated & Yes & Yes & Yes† & Not stated \\
\hline $\begin{array}{c}\text { National hospice } \\
(1986)^{19}{ }^{20} \ddagger \\
\end{array}$ & USA & Hospice & Yes & Some & Some & Some & Some & Some & Some & Some & Some \\
\hline $\begin{array}{l}\text { Wallston et al } \\
(1988)^{21} \ddagger\end{array}$ & USA & Hospice & Yes & Some & Some & Some & Some & Some & Some & Some & Some \\
\hline $\begin{array}{l}\text { McCorkle et al } \\
(1989)^{14} \S\end{array}$ & USA & Hospital & No & $\begin{array}{c}\text { Not } \\
\text { mentioned }\end{array}$ & $\begin{array}{c}\text { Not } \\
\text { stated }\end{array}$ & Not stated & Not stated & Not stated & Yes & Not stated & No \\
\hline $\begin{array}{l}\text { Cummings et al } \\
(1990)^{15}\end{array}$ & USA & Hospital & No & $\begin{array}{c}\text { Not } \\
\text { mentioned }\end{array}$ & Yes & Not stated & Not stated & Yes & Yes & Not stated & Not stated \\
\hline $\begin{array}{l}\text { Hughes et al } \\
(1992)^{22}\end{array}$ & USA & Hospital & No & $\begin{array}{c}\text { Not } \\
\text { mentioned }\end{array}$ & Yes & Not stated & Not stated & Not stated & Yes & Yes & Not stated \\
\hline $\begin{array}{l}\text { Addington-Hall } \\
\text { et al }(1992)^{24} \\
\end{array}$ & UK & Community care & No & $\begin{array}{c}\text { Not } \\
\text { mentioned }\end{array}$ & Yesी & Not stated & Not stated & Not stated & Not stated & Yes & Yes \\
\hline
\end{tabular}

Some=present in some institutions but not others in this multicentre study.

*Training programme for caregivers provided.

†General practitioner made no house visits.

fIn the national hospice study three groups of patients were studied: (a) hospice home care (with possibilities for admission); (b) hospice based home care (no beds available for admission); and $(c)$ control group. For our analyses the results of the first two groups were combined.

§Three groups of patients were studied: (a) oncology home care (with specialised oncology nurse); (b) standard oncology home care; and (c) standard care. For our analyses the results of the first two groups were combined.

१Team member could visit the patient at home but could not provide care.

Table 4 Essential findings of studies of home care programmes for patients with incurable cancer

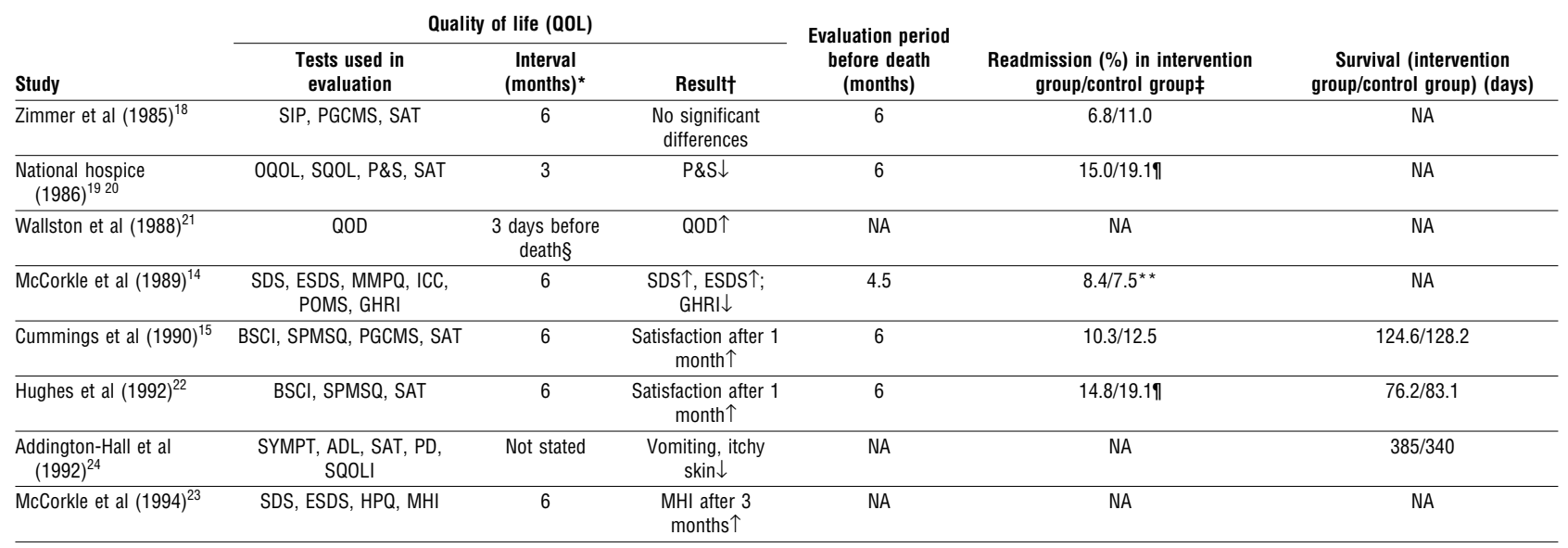

$\mathrm{SIP}=$ sickness impact profile; PGCMS=Philadelphia Geriatric Centre morale scale questionnaire; $S A T=t e s t$ for satisfaction; OQOL=overall quality of life scales; $S Q 0 L=S o c i a l$ quality of life scales; $\mathrm{P} \& S=$ pain and symptoms scales; $Q 0 D=$ =quality of death scale; $S D S=$ symptom distress scale; ESDS=enforced social dependency scale; MMPQ=McGill-Melzack pain questionnaire; ICC=inventory of current concerns; POMS=profile of mood status; GHRI=general health rating index; BSCl=Barthel's self care index; SPMSQ=short portable mental status questionnaire; SYMPT=questionnaire

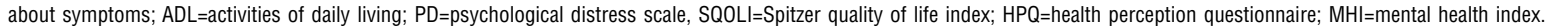

$N A=$ not analysed.

$\downarrow$ Worsened in the intervention group.

个Improved in the intervention group.

${ }^{\star}$ Time period after which the dependent variables were tested.

tOnly the dependent variables that were significantly influenced by the intervention are presented.

†Percentage of days that patients spent in hospital until death.

$\S$ As judged by the surviving spouse.

ISignificant difference.

${ }^{* *}$ Days spent in hospital for diagnosis or death excluded.

based in three studies, ${ }^{14}{ }^{15} 22$ hospice based in two studies, ${ }^{19}{ }^{21}$ community based in two studies, ${ }^{23}{ }^{24}$ and based at a rehabilitation centre in one study. ${ }^{18}$ The intervention and standard care programmes were poorly described. One study reported having a 24 hour service for their patients. ${ }^{18}$ In four studies the team members could visit patients at home. ${ }^{15} 1822{ }^{24}$ In one study technical home care (for example, intravenous infusions) was possible. ${ }^{23}$ In two studies a training programme for the patient and for his or her family and friends was included. ${ }^{15}$ In four studies regular team meetings were held. ${ }^{14} 151822$ In most studies a general practitioner and in only one study community nursing were available at home for patients in the control group. ${ }^{24}$

\section{Final results of studies}

The main findings of the studies are shown in table 4 . Two studies ${ }^{19}{ }^{24}$ reported fewer physical symptoms and one study less physical dependency among patients in the intervention group, ${ }^{14}$ whereas four studies did not find significant differences in this dimension. ${ }^{15} 182223$ 
With regard to the psychosocial dimensions, only one study out of the six that investigated this topic found a significant improvement in the "mental health index 5" questionnaire three months after starting the intervention. ${ }^{23}$

Of the five studies that investigated patients' satisfaction with care, two showed that patients were significantly more satisfied with the intervention programme than with standard care..$^{152}$

In five studies the readmission time could be calculated..$^{14151820}{ }^{22}$ All but one ${ }^{14}$ reported a lower readmission time for the intervention group. This difference reached significance in two studies. ${ }^{20}{ }^{22}$

When the results of the five randomised studies (which had the highest methodological scores) $)^{1415182224}$ were compared with those of the non-randomised studies (which had the lowest methodological scores), the outcome patterns turned out to be similar. Only two of the five randomised studies found positive effects on physical dimensions of the patients' quality of life, ${ }^{14}{ }^{24}$ none found positive effects on psychosocial dimensions, two out of the four studies evaluating satisfaction with care showed positive results, ${ }^{1522}$ and one out of the four studies that evaluated readmission time found positive effects on this outcome measure. ${ }^{22}$ Among the four nonrandomised studies ${ }^{19-2123}$ (of which two were combined $^{19-20}$ and one evaluated only "quality of death"21), one study showed positive effects on the physical dimensions, ${ }^{19}$ one showed positive effects on the psychosocial dimensions of the patients' quality of life, ${ }^{23}$ none showed positive effects on satisfaction with care, and one found positive results on readmission time. $^{20}$

Finally, we tried to relate the findings of the various studies to the type of intervention being applied. This was difficult because the interventions were poorly described in most studies (table 3). However, the ability of team members to visit patients at home and the incorporation of multidisciplinary team meetings into the programme seem to be important elements for achieving favourable outcomes. ${ }^{14} 1522$

\section{Discussion}

Our review shows that the effectiveness of home care programmes, when compared with standard care, for patients with terminal cancer still remains far from clear. Only nine studies investigated the effects of home care programmes on the quality of life of patients with terminal cancer or on their time spent in hospital before death. Two studies were combined because jointly they reported the results of the national hospice study on quality of life of patients and readmission time. Furthermore, one study ${ }^{22}$ reported the results of a subgroup analysis of a previously published investigation. ${ }^{15}$ The methodological quality of the studies was moderate considering the median score of 62 . The main shortcomings were found in the areas of population homogeneity, study design, comparability of groups, handling of drop outs, and blinding procedures. Furthermore, the findings of the various studies failed to show a consistent pattern. None of the studies, however, found a negative influence of home care interventions on quality of life or readmission time. Some even found a significantly positive influence on these outcome measures. No clear relation was observed between the various findings and the methodological quality of the studies (that is, when the randomised and non-randomised studies were compared). However, visiting patients at home and regular multidisciplinary team meetings seemed to be associated with positive findings.

\section{Shortcomings}

The results of this systematic review might, however, be criticised on several points. Firstly, it may be questioned whether all possible relevant articles were detected. We are reasonably confident that we did not miss other relevant published articles because, as recommended by others, ${ }^{25-28}$ we $(a)$ searched not only Medline but also CancerLit, Embase, and PsychLit; (b) made use of a combination of search terms in our literature search, using a combination of MeSH terms (indexing terms) and text words that covered a wide range of the research field; (c) tried other search strategies too; and (d) did not apply any language restrictions.

Secondly, it might be argued that studies on home care intervention programmes may have been missed because we excluded those studies using hospital inpatients as their control group. These were excluded because the main goal of this review was to give an overview of the effects of these home care intervention programmes on patients' quality of life and readmission time when compared to standard (primary) care. In our literature search we only found three studies that compared a home care intervention programme with hospital care. .9-31 $^{21}$

Thirdly, the choice and rating of the items measuring the methodological quality of studies might be criticised because these are prone to subjective preferences. The choice of items, however, was based on generally accepted principles of intervention research and covers several dimensions of methodological quality. ${ }^{17}$ The assignment of the various weights to the different items (table 1), on the other hand, is by nature more subjective. If, however, others think that different weights should be assigned to the various criteria, they can easily devise their own methodological scores using table 2 and their own rating list.

Fourthly, it has to be recognised that eight out of the nine studies included in this study were from the United States. The other one was from the United Kingdom. The result of this review cannot therefore be translated to other countries. The obvious difference between the number of studies performed in the United States and those performed in other parts of the world with highly developed healthcare systems (such as northwest Europe) may be explained by the United States's less well developed primary care system. Therefore, the need for home care programmes for chronically ill patients with complex problems in the United States may be higher. This difference in the primary care systems between these two parts of the world, and the fact that most of the controlled studies on the effectiveness of home care programmes were performed in the USA, shows the urgent need for further research on this subject in northwest European countries. 
Key messages

- Only nine controlled prospective studies have compared the effects of home care intervention programmes for patients with terminal cancer with those of standard care, in relation to patients' quality of life and time spent in hospital between start of care and death

- The methodological quality of these studies seemed to be moderate

- Home care programmes did not have a negative influence on quality of life or time spent in hospital; some studies observed positive effects on these outcome measures

- Enabling team members to visit patients at home and holding regular multidisciplinary team meetings seem important elements for obtaining favourable results

- The general belief that home care programmes are effective for patients with terminal cancer is not supported scientifically

\section{Conclusion}

The fact that the effectiveness of home care programmes for patients with terminal cancer still remains unclear seems to contrast with what is generally believed by patients, professional caregivers, and politicians working in health care, given the extensive development of home care programmes in several countries. ${ }^{32-36}$ Further properly designed studies are therefore urgently needed to elucidate the effects of these home care programmes. This is particularly true for northwest Europe. We found that the programmes that enabled team members to visit patients at home or incorporated multidisciplinary team meetings had positive outcomes, so future investigators should incorporate these two elements in their programmes.

We greatly appreciate the support given by Shaun Cardiff in translating the manuscript.

Contributors: FWJMS devised and instigated the study and performed the literature searches. He and JCMvanH identified the articles from the literature search that met the inclusion criteria for this study and scored the methodological quality and effectiveness of the various studies. The paper was written by FWJMS, JCMvanH, LPdeW, and HFJMC (who is also the guarantor).

Funding: Scientific Fund of the Catharina Hospital Eindhoven, Netherlands.

Conflict of interest: None.

1 Fraumeni JF, Hoover RN, Devesa SS, Kinlen LJ. Epidemiology of cancer In: Devita VT, Hellman S, Rosenberg SA, eds. Cancer. Principles and prac tice of oncology. Philadelphia: Lippincott, 1993:196-236.

2 Steering Committee on Future Health Care Scenarios. Cancer in the Netherlands: scenarios on cancer 1985-2000. Dordrecht: Kluwer Academic 1988.

3 Macdonald $\mathrm{N}$. The interface between oncology and palliative medicine. In: Doyle D, Hanks GWC, MacDonald N, eds. Oxford textbook of palliative medicine. Oxford: Oxford University Press, 1997:11-7.

4 Ahmedzai S. Quality of life research in the European palliative care setting. In: Osaba D, ed. Effect of cancer on quality of life. London: CRC Press, 1991:323-32.

5 Van den Akker PAM, Tits MHL, Kok NM. Leven met de dood. Over terminale patienten en terminale zorg in Nederland [Living with death. Terminal patients and terminal care in the Netherlands]. Houten: Bohn Stafleu Van Loghum, 1994.

6 Field D, James N. Where and how people die. In: Clark D, ed. The future of palliative care. Buckingham: Open University Press, 1993:6-29.

7 Jones RV, Hansford J, Fiske J. Death from cancer at home: the carers' perspective. $B M J$ 1993;306:249-51.

8 Wilkes E. Dying now. Lancet 1984;i:950-2
9 O'Hare PA, Yost LS, McCorkle R. Strategies to improve continuity of care and decrease rehospitalization of cancer patients: a review. Cancer Inves 1993;11:140-58.

10 Conkling VK. Continuity of care issues for cancer patients and families. Cancer 1989;64:290-4.

11 Lubitz JD, Riley GFR. Trends in medicare payments in the last year of life. NEngl J Med 1993;328:1092-6.

12 Townsend J, Frank AO, Fermont D, Dyer S, Karron O, Wallgrove A, et al. Terminal cancer care and patients' preference for place of death: a prospective study. BMJ 1990;301:415-7.

13 Dunlop RJ, Davies RJ, Hockley JM. Preferred versus actual place of death: a hospital palliative care support team experience. Palliat Med 1989;3:197-201.

14 McCorkle RG, Benoliel JQ, Donaldson G, Georgiadou F, Moinpour C, Goodell B. A randomized clinical trial of home nursing care for lung cancer patients. Cancer 1989;64:1375-82.

15 Cummings JEB, Hughes SL, Weaver FM, Manheim LM, Conrad KJ, Nash $\mathrm{K}$, et al. Cost-effectiveness of Veterans Administration hospital-based home care. A randomized clinical trial. Arch Intern Med 1990;150: 1274-80.

16 Moher D, Fortin P, Jadad AR, Juni P, Klassen T, Le Lorier J, et al. Completeness of reporting of trials published in languages other than English: implications for conduct and reporting of systemic reviews. Lancet 1996:347:363-6.

17 Moher D, Jadad AR, Nichol G, Penman M, Tugwell P, Walsh S. Assessing the quality of randomized clinical trials: an annotated bibliography of scales and checklists. Controlled Clin Trials 1995;16:62-73.

18 Zimmer JG, Groth-Junker A, McCusker J. A randomized controlled study of a home health care team. Am J Public Health 1985;75:134-41.

19 Greer DS, Mor V, Morris JN, Sherwood S, Kidder D, Birnbaum H. An alternative in terminal care: results of the national hospice study.J Chronic Dis 1986;39:9-26.

20 Mor V, Kidder D. Cost savings in hospice: final results of the national hospice study. Health Services Research 1985;20:407-22.

21 Wallston KA, Burger C, Smith RA, Baugher RJ. Comparing the quality of death for hospice and non-hospice cancer patients. Med Care 1988;26:177-82.

22 Hughes SL, Cummings J, Weaver F, Manheim L, Braun B, Conrad K. A randomized trial of the cost effectiveness of VA hospital-based home care for the terminally ill. Health Services Research 1992;26:801-17.

23 McCorkle R, Jepson C, Malone D, Lusk E, Braitman L, Buhler-Wilkerson $\mathrm{K}$, et al. The impact of posthospital home care on patients with cancer Research in Nursing and Health 1994;17:243-51.

24 Addington-Hall JM, MacDonald LD, Anderson HR, Chamberlain J, Freeling P, Bland JM, et al. Randomised controlled trial of effects of coordinating care for terminally ill cancer patients. BMJ 1992;305:1317-22.

25 Oxman AD, Cook DJ, Guyatt GH. User's guide to the medical literature. VI. How to use an overview. JAMA 1994;272:1367-71.

26 Dickersin K, Scherer R, Lefebvre C. Identifying relevant studies for systematic reviews. BMJ 1994;309:1286-91.

27 Haynes RB, Wilczinsky N, McKibbon KA, Walker CJ, Sinclair JC. Developing optimal search strategies for detecting clinically sound studies in Medline. J Am Med Informatics Assoc 1994;1:447-58.

28 Greenhalgh T. How to read a paper. The Medline database. $B M J$ 1997;315:180-3

29 Ventafridda V, De Conno F, Vigano A, Ripamonti C, Gallucci M, Gamba A. Comparison of home and hospital care of advanced cancer patients. Tumori 1989;75:619-25

30 Dessloch A, Maiworm M, Florin I, Schulze C. Krankenhauspflege versus Hauskrankenpflege: zur Lebensqualitat bei terminalen Tumorpatienten [Hospital care versus home care: on quality of life of patients with terminal cancer]. Psychotherapie, Psychosomatik, Medizinische Psychologie nal cancer].
$1992 ; 42: 424-9$.

31 Vinciguerra V. A comparative assessment of home versus hospital comprehensive treatment for advanced cancer patients. J Clin Oncol 1986;4:1521-8.

32 Parkes CM. Terminal care: evaluation of an advisory domiciliary service at St Christopher's hospital. Postgrad Med J 1980;56:685-9.

33 Seale C. A comparison of hospice and conventional care. Soc Sci Med 1991;32:147-52.

34 Lang Meier M, Neuenschwander H. Hospice-a homecare service for terminally ill patients in southern Switzerland. Support Care Cancer 1995;3:389-92.

35 Tsamandouraki K, Tountas Y, Trichopoulos D. Relative survival of terminal cancer patients in home versus hospital care. Scand J Soc Med 1992;20:51-4.

36 Beck-Friis B, Strang P. The organization of hospital-based home care for terminally ill cancer patients: the Motala model. Palliat Med 1993;7:93-100

(Accepted 19 February 1998)

\section{Appendix}

The following criteria were used to assess methodological quality of the studies in this review. Altogether, 34 items had to be scored (providing a maximum total score of 100).

A Selection and homogeneity

Inclusion and exclusion criteria clearly described: 1 point; investigation confined to a homogeneous study population of terminal cancer patients (prognosis $<6$ months): 5 points 


\section{B Design}

Randomised design: 7 points; randomisation procedure described and adequate: 4 points; randomisation procedure inappropriate: -3 points

C Comparability of groups

Groups comparable for duration of disease, age, sex, treatment, comorbidity, coping behaviour, social economic status, social network and baseline outcome measure: 1 point per item

D Drop out handling

Drop outs $<10 \%,<30 \%,<50 \%: 3$ points, 2 points, and 1 point respectively. Number of drop outs is presented for every group: 1 point. Reasons for drop out are mentioned: 2 points

E Number of patients included

Smallest group after inclusion contained $>25$ patients: 6 points; $>50$ patients: 9 points; $>75$ patients: 15 points F Description of interventions and standard care

Participants in the intervention or standard care programme are described: 3 points per description. Intervention programme or standard care programme is described adequately so that others can replicate it: 4 points per description; programme is described partially: 2 points per partial description; site of intervention mentioned: 1 point
G Simultaneous interventions

No simultaneous interventions: 6 points; comparable simultaneous interventions: 3 points

$\mathrm{H}$ Blinding of people who collected outcome measures If yes: 5 points.

I Use of appropriate outcome measures to test quality of life Term "quality of life" clarified: 2 points; quality of life measured in a multidimensional way: 2 points; explanation of why test was used: 2 points; patients judged their own quality of life: 2 points

$\mathrm{J}$ Follow up

Outcome measures collected in the intervention and control group at equal time intervals: 3 points; outcome measures collected at least 1 month after starting intervention: 3 points

$\mathrm{K}$ Statistical analysis

Author(s) investigated possibility of selection bias owing to drop out: 1 point; drop out was not selective: 3 points; authors corrected findings for possible confounding factors and no confounding factors were present (as in adequately designed randomised studies): 6 points.

L Data presentation

Authors presented the mean of the dependent variables: 3 points

\title{
Routine replacement of central venous catheters: telephone survey of intensive care units in mainland Britain
}

\author{
A M Cyna, J L Hovenden, A Lehmann, K Rajaseker, P Kalia
}

Editorial by O’Leary and Bihari

Department of Anaesthesia Hartlepool Distric General Hospital,

Hartlepool,

Cleveland

TS24 9AH

A M Cyna,

consultant

A Lehmann,

senior house officer

K Rajaseker,

locum consultant

P Kalia,

consultant

Pathology Department, Hartlepool Distric General Hospital

J L Hovenden, consultant microbiologist

Correspondence to: Dr Hovenden

BMJ 1998;316:1944-5
The incidence of sepsis with duration of central venous catheterisation remains controversial. Although some authors routinely replace central venous catheters, ${ }^{12}$ this practice is not supported by data from randomised, controlled studies. ${ }^{3}{ }^{4}$ We surveyed intensive care units in mainland Britain to determine whether central venous catheters are replaced routinely.

\section{Subjects, methods, and results}

We conducted a telephone survey in the first two months of 1997 of all general intensive care units in mainland Britain mentioned in the Directory of Emergency and Special Care Units 1996. We spoke to the consultant when available or the senior sister on duty and asked about their current practice of replacing central venous catheters. Of the 169 units contacted, 165 agreed to participate, two were busy, and two refused to respond. We asked three questions: Does your intensive care unit practise routine scheduled replacement of central venous catheters? If so, for how long are catheters left in place before replacement? What is your current practice based on (research, audit, microbiology advice, no reason given)? Any additional comments were noted.

Eighty six of the respondents $(52 \%)$ routinely replaced central venous catheters, leaving them in place for a mean of 6.5 days (SD 1.6, range 2-14 days); replacement was also scheduled by 22 of the 37 teaching hospitals $(60 \%)$ and 64 of the 128 non-teaching hospitals $(50 \%)$. The figure shows the distribution of the units' practice according to the number of days before central venous catheters were replaced. Of the 86 units routinely replacing catheters, 23 based their practice on published research, three on local clinical audit, and nine on advice from their microbiology department, while 51 could not give a reason. Two units had been advised by their microbiology departments not to practise routine replacement; seven units said that their practice depended on the consultant on duty; two units had abandoned the practice in the past two years; one unit's practice was arbitrary; one unit's practice was pragmatic; and four units were in the process of implementing a policy.

\section{Comment}

Our survey shows that the routine replacement of central venous catheters in intensive care units in mainlaind Britain is variable. Examples of indications for replacement of central venous catheters included blocked lumens, inflamed entry sites, and suspected sepsis related to the catheter. Recent recommendations from the United States suggest that non-tunnelled cen- 